\title{
Interview
}

\section{De grote toezichtsinterviewestafette}

\section{Deel 5: De Nederlandsche Bank}

\author{
Joep Beckers en Anna Merz*
}

Voor deze aflevering van het estafette-interview spraken Joep Beckers en Anna Merz namens de redactie van Tijdschrift voor Toezicht met Else Bos, sinds 1 juli 2018 toezichtdirecteur en voorzitter toezicht bij De Nederlandsche Bank. Mede naar aanleiding van de suggesties van Monique Verdier, vicevoorzitter in de raad van bestuur en Katja Mur, lid van de raad van bestuur bij de Autoriteit Persoonsgegevens (AP), die we interviewden voor nummer 2020-3 van Tijdschrift voor Toezicht, spraken wij met Else Bos over de belangrijkste uitdagingen voor toezichthouders, de impact van de coronacrisis, duurzaamheid en digitalisering.

Dr. J. Beckers is hoofdredacteur van het Tijdschrift voor Toezicht en manager Toezicht Zorgaanbieders bij de NZa. A. Merz (MA) is redactielid bij Tijdschrift voor Toezicht en promovenda criminologie bij de Erasmus Universiteit Rotterdam

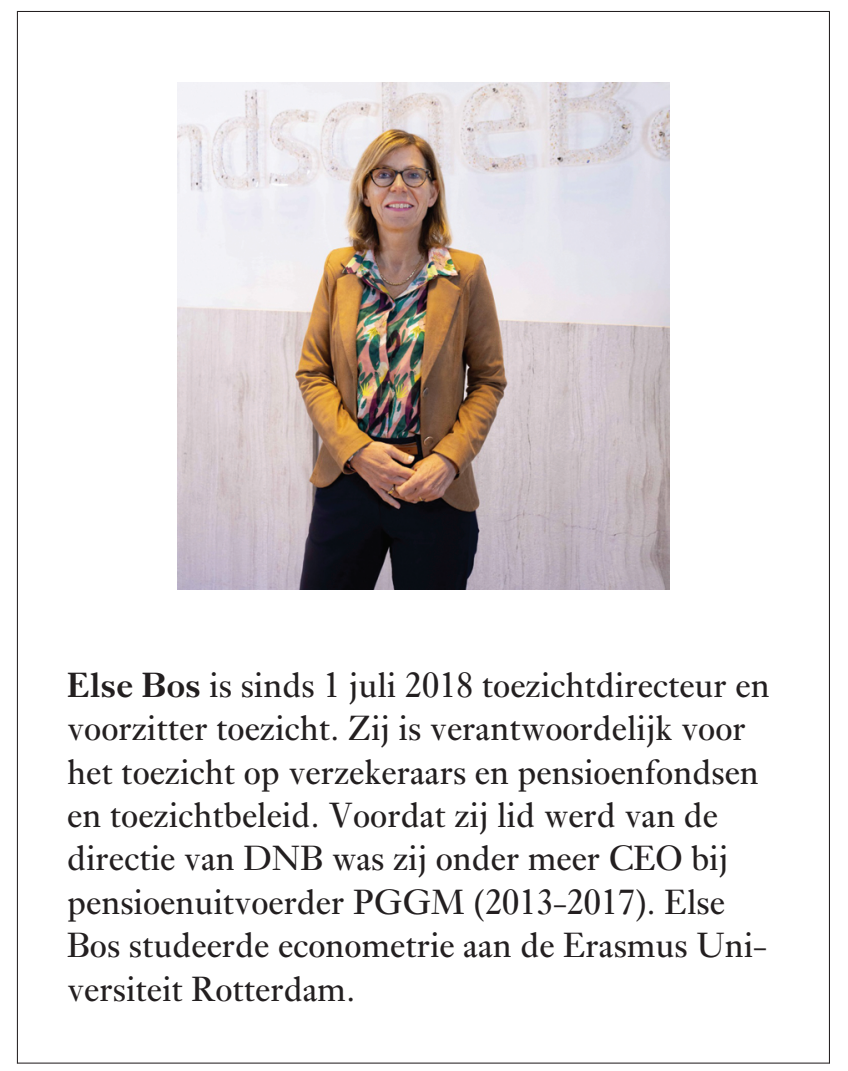

Joep \& Anna: We zouden graag beginnen met de vraag mat nou het allerleukste is a an het merken bij DNB. Fij bent ook bestuursvoorzitter gemeest bij PGGM, we zijn ook wel benieumd hoe dan de huidige rol bij DNB zich verhoudt tot die vorige rol. Wat valt op?

Else: Er zijn verschillen en er zijn overeenkomsten. Wat ik in mijn werk heel belangrijk vind, is de mensen waar ik mee werk. En ik werk bij DNB met gemotiveerde, betrokken, energieke en slimme mensen. Dat is gewoon 
fijn werken. De rol bij DNB is maatschappelijk relevant, en dat is voor mij ook een heel belangrijk onderdeel van mijn werk. Wat een verschil is, en dat maakt natuurlijk dat het voor mij weer nieuw en anders was, is dat het perspectief veel breder is. In plaats van één instelling, kijk je nu naar alle instellingen. Niet alleen naar één sector, maar naar de breedte, naar meerdere financiële sectoren of subsectoren. Niet alleen in Nederland, maar ook in Europa. Zelfs nog breder dan dat. Wat verder een beetje anders is dan werken bij PGGM, maar ook werken bij banken, is dat je wat verder af staat van de mensen waar het om gaat. De deelnemers, de polishouders, de klanten, die afstand is groter. Terwijl ik het wel altijd heel belangrijk vind om iedere keer voor ogen te houden dat dat uiteindelijk hetgene is waar je het allemaal voor doet. En wat, tot slot, ook wel anders is: ik ben van de commerciële sector naar de publieke sector gegaan, dat is gewoon anders werken.

Joep \& Anna: Dat tweede punt, die grotere afstand. Dat is voor veel toezichthouders herkenbaar. Doen jullie dan specifieke dingen om die afstand wat te verkleinen?

Else: De directe contacten zijn vooral de contacten met instellingen en in dat contact spreken we natuurlijk veel tegen de achtergrond van het belang van de polishouder of het belang van de deelnemer, daar bevragen we de instellingen ook op. Wij hebben geen directe contacten met de klanten. Het direct behartigen van de belangen van klanten, bijvoorbeeld als het gaat om de communicatie tussen financiële instellingen en hun klanten, ligt primair bij de Autoriteit Financiële Markten (AFM). Dus ik denk dat we er ook goed op moeten letten dat die rolverdeling zuiver blijft. Bij ons is de relatie met de klanten wat indirecter. Heel veel gesprekken die we met elkaar voeren gaan over: is dit in belang van de polishouder, is dit in belang van de deelnemer? Op de achtergrond is het voortdurend aanwezig maar in het directe contact niet.

Joep \& Anna: Dat geldt natuurlijk voor meerdere toezichthouders. Toezichthouders missen soms ook een mat directere feedbackloop. Fe kunt met allerlei hele slimme collega's maar ook met relevante stakeholders een mooie toezichtaanpak bedenken. Die rol je vervolgens uit. Maar hoe landt dat dan eigenlijk bij de mensen die er echt mee te maken hebben in de praktijk? Hoe ervaren zij nou eigenlijk ons toezichtaanpak?

Else: Dat herken ik wel. We doen wel stakeholderonderzoeken en dan proberen we feedback breed op te halen. Ook wat het maatschappelijk perspectief is, om het zo maar te zeggen. Want het maatschappelijk draagvlak is voor ons uiteraard heel belangrijk.

Joep \& Anna: Eigenlijk zijn we al naar de uitdagingen en kansen aan het over gaan. Als we jou, Else, nu die vraag stellen, wat zie jij nou als de grootste uitdagingen en kansen voor jullie eigen organisatie, DNB, maar misschien ook breder gemoon voor het toezicht in Nederland?
Else: Dat is nog best moeilijk kiezen. Het begint toch, dat valt niet te ontkennen, bij de actualiteit. De coronacrisis heeft zeker impact op de maatschappij, op de economie, op financiële instellingen, dus ook op ons. En met name de onzekerheid over de toekomst en over hoe we precies uit deze crisis komen, is een grote uitdaging. Dat is er in ieder geval een. Ik denk een tweede die daar bijkomt maar van veel langere duur is, is de lage rente. Met name de lange periode van een lage rente. Vooral voor de verzekeraars en pensioenfondsen is dat heel ingewikkeld. Een derde uitdaging waar wij mee te doen hebben, net zoals vele, is het nieuwe pensioencontract. En, tot slot, de hele digitalisering en alle vragen rondom duurzaamheid.

Joep \& Anna: Misschien ligt het voor de hand om nu maar te beginnen met corona, de meest actuele van alle uitdagingen mellicht. Hoe heeft de coronacrisis impact op het toezicht van $D N B$ ?

Else: Op verschillende manieren. Om te beginnen natuurlijk gewoon op de mensen. Zoals iedereen, werken wij nog steeds overwegend vanuit huis. Dat is voor iedereen een andere manier van werken, met plussen en met minnen. In het begin was het wennen en zorgen dat je de tools op orde hebt. Dat ging bij bijna iedereen best goed. Maar daarna merk je dat het voor mensen belangrijk is om een evenwicht te vinden. Wat is een goede balans tussen zakelijk en privé? Hoe doe je dat als je vanuit huis werkt? En wat we nu vooral merken, is dat thuiswerken echt een tijdje best goed ging en ook op allerlei plekken wel efficiëntie met zich meebracht, maar dat mensen toch het sociale contact missen. En zeker als het gaat om vraagstukken waarbij creativiteit of verdieping nodig is, en we elkaar moeten inspireren. Dat is echt een uitdaging. Het tweede is dat corona ook op ons toezicht een directe impact heeft. Op de manier waarop wij toezicht houden. Dat zit in een paar dingen. Er zijn allerlei maatregelen genomen richting de instellingen. Vooral bedoeld als een stukje operationele relief. Langere tijdslijnen voor rapportages, uitstel van stresstesten, dat soort dingen. Wat we ook nog steeds niet kunnen doen, zoals we dit altijd deden, zijn on-site onderzoeken. Daar hebben we nu off-site onderzoeken voor in de plaats. Dat zijn deep dives op bepaalde onderwerpen, waar je normaal gesproken bij een instelling op bezoek gaat om te kijken hoe het echt loopt. Dat kan nu niet, dat moet dus op een ander manier. Daarnaast is er op sommige plekken relief geboden, in termen van de eisen die we stellen. Zo heeft DNB een aantal toezichteisen tijdelijk versoepeld, zoals verlaging van systeembuffers voor de drie grootbanken en het uitstel van de maatregel voor banken om meer kapitaal aan te houden voor hun hypotheekportefeuilles. Overigens geldt dit vooral bij banken, niet zozeer bij verzekeraars en pensioenfondsen. Er is op Europees niveau een dividendstop afgekondigd die we in Nederland hebben gevolgd. Het derde blok van impact, tot slot, dat is de klap die de economie heeft gekregen en de onzekerheid van het herstel. 
Joep \& Anna: Interessant. Als we ze gemoon afpellen. Deel een mas de mensen. Een punt dat je noemde, is het gemis van sociaal contact of het gemis van contact überhaupt. En dan met name als het gaat over contact waar een stuk creativiteit of verdieping is gemenst. Welke oplossingsrichtingen hebben jullie daarvoor bedacht en mat kunnen andere toezichthouders daarvan leren?

Else: We hebben wel tegen elkaar gezegd: 'we willen niet helemaal terug naar hoe het was'. We willen heel bewust op zoek naar een meer hybride manier van werken. Daarbij hebben we overigens ook tegen elkaar gezegd dat je niet al te vroeg je conclusies moet trekken. Want wat ik ook zei, dingen die in het begin nog best als plezierig werden ervaren blijken toch ook op een gegeven moment lastiger vol te houden. En andere dingen ga je pas op de langere duur wat meer missen. Dus je moet je zelf wel wat tijd gunnen. Kortom, we zijn druk bezig met het uitwerken van ideeën rond hybride kunnen werken, dus een deel van de mensen is op kantoor en een deel werkt op afstand, met het afwisselen van fysieke en digitale meetings, en met minder internationaal reizen. De internationale meetings proberen we op z'n minst voor een deel digitaal te doen. Dat zijn de dingen waar we mee bezig zijn. Daarnaast zijn we ook ons pand aan het verbouwen. Ook daarbij gaan we kijken welke impact de huidige crisis heeft op de wat langere duur en of dat ook betekenis heeft voor de manier waarop je het pand gaat inrichten. De verwachting is dat je veel meer behoefte krijgt aan ruimte om te ontmoeten en veel minder aan individuele werkplekken. Als mensen rustig in hun eentje willen werken, dan kunnen ze dat veelal ook thuis doen. Elkaar echt ontmoeten doe je juist op kantoor.

Joep \& Anna: En het tweede blokje mas toezicht. Fij geeft aan dat corona best mel mat impact heeft gehad op de manier maarop jullie toezicht uitoefenen. Even om het helemaal scherp te krijgen: on-site onderzoeken gaan dus op het moment helemaal niet door. Die zijn vervangen door off-site onderzoeken. Of doen jullie toch ook nog iets on-site?

Else: In eerste instantie helemaal niet, inmiddels sporadisch. Beetje afhankelijk van de regels die de instelling hanteert. En dat in combinatie met de regels die we zelf hanteren. Zoals gezegd, hebben we ook een instrument aan onze toolbox toegevoegd: de off-site onderzoeken. Dat zijn wel die deep dives, die themagerelateerde onderzoeken, maar dan op afstand. We willen natuurlijk uiteindelijk wel weer terug naar de on-site onderzoeken. Het is niet de verwachting dat dat niet meer nodig is. Waarbij we wel denken dat die off-site onderzoeken die we nu ontwikkelen ook een blijvend instrument zouden kunnen zijn. In die zin leer je ook weer van zo'n crisis. Zo ook met digitaal vergaderen, dat is iets wat iedereen natuurlijk in een crash course heeft moeten leren.

Joep \& Anna: Een van de aspecten maar jullie onderzoeken naar doen en gericht naar kijken is cultuur en gedrag. Als we nu toch al bij de onderzoeken stil staan, hoe gaan jullie met dat soort onderzoeken om ten tijde van coro$n a ?$

Else: Governance, gedrag en cultuur is eigenlijk een drieslag waar DNB alweer een aantal jaar geleden mee is gestart. Omdat op een gegeven moment bleek dat als je gaat kijken naar de root causes, de onderliggende oorzaken van veel problemen, dat die vaak toch gevonden werden in gedrag en cultuur. Dat is een trigger geweest. Gedrag en cultuur heeft vanuit dat perspectief dan ook invloed op de soliditeit van een organisatie, op het risicoprofiel. Dat loopt mee in veel van de onderzoeken die we doen. Waar gaat het dan om? Dan gaat het om board dynamics, hoe opereert een board en het senior management in een organisatie, hoe gaan die met elkaar om? Hebben die de taken goed verdeeld? Is scherp wie welke verantwoordelijkheid draagt? Wordt dat goed uitgevoerd? Dat soort vraagstukken. Tweede vraagstuk dat daar vaak bij aan de orde komt, en dat past ook wel bij de grote dynamieken in de sector, dat is het thema wendbaarheid. En dan niet alleen de technische wendbaarheid van de organisatie, dus zijn ze in staat om hun systemen aan te passen? Maar als het over governance en cultuur gaat, dan gaat het voornamelijk om de mentale wendbaarheid. Zijn bestuurders in staat om regelmatig toch even een beetje afstand te nemen tot wat ze bedacht hebben en wat ze doen om te kijken of het nog steeds wel klopt bij alles wat er om hen heen gebeurt. En of ze voldoende op de lange termijn met goede dingen bezig zijn. Het derde thema daarbij is risico en risicocultuur. En dan kom je ook bij het leiderschap van een organisatie. Hoe wordt er omgegaan met risico's? Worden risico's gemitigeerd? Hoe worden mensen geholpen om zich te gaan realiseren dat risico's er altijd zijn? Dus je moet ze mitigeren, maar je moet ook accepteren dat ze zich op enig moment kunnen effectueren en hoe ga je er daar dan mee om en hoe breng je dat in de cultuur van je organisatie? Dat zijn de thema's die daarin voor ons belangrijk zijn.

Joep \& Anna: Dat zijn mel thema's maar me ons van kunnen voorstellen dat de huidige crisis invloed heeft op de manier maarop je hierop toezicht houdt.

Else: Ik denk eigenlijk andersom. Als deze factoren goed verankerd en goed beheerst zijn in een organisatie, dan denk ik dat je een crisis gemakkelijker het hoofd biedt dan wanneer dat niet zo is.

Joep \& Anna: Fe zegt eigenlijk, dit zijn randvoormaardelijke elementen. Als je die randvoormaarden hebt ingevuld, dan vermacht je dat zo'n instelling veel beter met zo'n crisis kan omgaan dan als dat niet het geval is.

Else: Ja. Dat is ook waarom gedrag en cultuur in ons toezicht nooit op zichzelf staat. Het is altijd een onderdeel van het bredere financiële en integriteitstoezicht. Dat stond volgens mij ook in een van jullie vragen: wat zou je dan willen meegeven aan andere toezichthouders? Nou, ik denk dit. Denken vanuit root causes, met gedrag en cultuur als onderdeel van het bredere 
geheel. Maar het is ook een thema waar je langdurig aandacht aan moet besteden. En waar natuurlijk duurzame verandering relevant is. Het is niet iets waar je er even naar kunt kijken en dan ga je weer. Dat ervaren we allemaal, ook in ons eigen organisaties, dat cultuur iets is wat heel diep in een organisatie zit. Je verandert de cultuur niet zomaar even. Het valt niet mee om een cultuur te veranderen. Je kunt de sterkere dingen sterker maken en de zwakkere dingen proberen te versterken. Maar het is in ieder geval iets van de lange adem.

Joep \& Anna: In de wat bredere toezichtwereld zijn er natuurlijk steeds meer toezichthouders die zich zijn gaan bezighouden met governance, gedrag en cultuur. Eigenlijk vanmege dezelfde onderliggende redenen, dat je op zoek wilt naar de dieperliggende oorzaken, daar wil je aan kunnen draaien om echt structurele verbeteringen te kunnen opleveren. En tegelijkertijd merk je in ieder geval in sommige sectoren dat ondertoezichtgestelden het soms mel mat ingemikkeld vinden. Want de toezichthouder die zie kenden van een vrij grote afstand die komt opeens best dichtbij. De cultuur van een organisatie is iets mat heel erg eigen is. Wat heeft de toezichthouder daar over te zeggen of van te vinden? Is dat nog een sentiment dat jullie in jullie praktijk ook tegenkomen of is het, omdat jullie hier al langere tijd aandacht aan besteden, een meggehaalde hobbel zeg maar?

Else: Ik denk dat wij die hobbel grotendeels weggehaald hebben. Maar hij is er zeker wel. Maar juist door dit aan te vliegen vanuit de kerntaak financieel integriteitstoezicht, vanuit dat thema van root causes, van andere issues. En dan zie je ook wel als je dit soort gesprekken voert met onder toezicht staande instellingen, dat ze dat ook wel herkennen. Maar het ene gesprek is makkelijker dan het andere.

Joep \& Anna: Met een schuin oog op de tijd, iets wat we in ieder geval met elkaar moeten besproken hebben straks is de estafettevraag van de Autoriteit Persoonsgegevens. Wij hebben de vraag van de AP geplaatst in het dilemma maarbij je als nationale autoriteit moet opereren in een internationaal speelveld. De AP heeft het over de spanning die dit met zich mee kan brengen. Maar eerst iets opener geformuleerd: hoe ervaren jullie dat eigenlijk? Opereren als nationale toezichthouder binnen een internationaal speelveld?

Else: De vraag zoals die geformuleerd was, klonk voor mij een beetje als 'dit overkomt je en daar heb je dan last van'. Dat zou ik willen omdraaien. Nederland is een kleine en ook open economie. Dat betekent dat we profiteren van Europa en dat we ook profiteren van Europees toezicht. Dat is het startpunt. Vervolgens zijn wij binnen Europa de grootste van de kleintjes. Dat betekent dat we relatief veel invloed hebben. En het betekent ook dat we die invloed moeten gebruiken. Daar investeren we ook in. We proberen ervoor te zorgen dat we de goede ideeën die we hebben naar Europa brengen. Om daar concrete voorbeelden van te geven: het AMLtoezicht, het witwastoezicht in Nederland, daar zijn we natuurlijk al een tijd mee bezig. Daar hebben we ons best voor gedaan en dat doen we nog steeds, om ervoor te zorgen dat dat op Europees niveau de goede plek krijgt. En ook het gedrag- en cultuurtoezicht, waar we het net over hadden, is iets wat we in Nederland doen maar wat we ook in Europa op de kaart proberen te zetten. Digitalisering is iets waar wij op inzetten, maar wat we ook naar Europa brengen. Met andere woorden: als je ervoor zorgt dat je er dingen brengt, dan heb je daar ook heel veel profijt van.

Joep \& Anna: Wij kunnen ons goed voorstellen, bijvoorbeeld als het gaat om gedrag en cultuur, dat jullie relatief vooroplopen, dus dat jullie vooral mat brengen en jullie Europese collega's daarin meenemen, en zo gezamenlijk zorgen voor een robuuster financieel stelsel. Maar zijn er ook specifieke dingen die jullie daar hebben gehaald? Die jullie hebben opgestoken van andere toezichthouders?

Else: We moeten ons natuurlijk in ieder geval aan de Europese toezichtkaders conformeren. Daar zitten soms elementen in die wij misschien zelf niet op die manier bedacht zouden hebben. En soms zijn we daar oké mee en soms denken we 'dat moet dan maar even'. In de breedte is het heel belangrijk dat we zo veel mogelijk consistentie en convergentie hebben. We streven harmonisatie op Europees niveau na. En dat is ook heel belangrijk voor een kleine en open economie zoals Nederland. Dat brengt overigens ook veel werk met zich mee. Soms lijkt het misverstand te bestaan dat het toezicht op de grote banken naar Europa is verhuisd en dat DNB daar dan niks meer aan hoeft te doen. Dat is gewoon niet waar. Want de teams die op de grote banken zitten, die bestaan voor het grootste deel uit DNB'ers en daar wordt dan een aantal mensen uit Europa aan toegevoegd.

Joep \& Anna: Even terug naar de dilemma's in toezichtland. Welke dilemma's zien jullie dan?

Else: We hebben er een aantal al geraakt. Waar we nog niet zo aan geraakt hebben, is het thema 'digitaal'. Dat hoort voor mij bij het dilemma 'streng toezicht versus kans voor innovatie'. Digitalisering is wat mij betreft langs twee lijnen belangrijk. De ene lijn is: de instellingen digitaliseren in hoog tempo. Dat is al een tijd aan de gang en dat gaat door. Er komen ook allerlei nieuwe spelers op de markt. Of dat nou nieuwe spelers in bestaande productomgevingen zijn of hele nieuwe productomgevingen. Ik vind het ongelofelijk belangrijk dat wij als DNB weten maar vooral ook begrijpen wat er gebeurt en op welke manier zij hun dienstverlening inrichten en hoe zij zich dan bedienen van allerlei digitale middelen en digitale tools en welke risico's daarmee gepaard gaan. Want als je dat niet begrijpt, dan vul je alles maar in. En als je het wel begrijpt, dan kun je veel beter onderscheid maken tussen wat een risico en wat eigenlijk een oplossing is. Dat is de ene as. En daar hoort ook bij dat je door het goed te begrijpen de sector niet blokkeert en innovatie de ruimte geeft. De andere as is dat ook onze eigen werkomgeving en onze eigen inrichting moet digitaliseren. In onze processen maar ook bijvoorbeeld in onze manier van werken. 
Joep \& Anna: De eerste as die je noemde, meten en begrijpen mat er gebeurt. Hoe zorg je ervoor dat je weet en begrijpt wat er gebeurt?

Else: Dat kan op verschillende manieren. Een van de dingen is een iForum dat we hebben opgericht. Dat is een platform met en voor de sector waar we allerlei vraagstukken op het gebied van digitalisering met elkaar delen en waar we ook experimenten doen met elkaar. Waar DNB en spelers uit de sector met elkaar bepaalde vraagstukken oppakken. Wat al langer loopt, is bijvoorbeeld een blockchainexperiment. We zijn nu bezig met een experiment om te kijken naar real time toezicht, werken met artificial intelligence. Op die manier, door samen dat soort vraagstukken op te pakken, leer je natuurlijk.

Joep \& Anna: Merk je daar nog iets van een aarzeling van de kant van partijen maarmee jullie samenmerken? Fullie blijven de toezichthouder, en samenmerken met de toezichthouder kan misschien ook als mat merkmaardig of ongemakkelijk morden ervaren. Merk je daar iets van?

Else: Tot nu toe niet. We bespeuren juist heel veel enthousiasme.

Else: Ik merk trouwens dat het thema 'vooruitkijken' heel centraal staat. Dat zit bij gedrag en cultuur, bij duurzaamheid, bij digitalisering en, dat wilde ik nog toevoegen, dat zit ook in de actualiteit. Als je kijkt waar we nu zitten in de coronacrisis, de onzekerheid et cetera, dan denken we in termen van scenario's. Wat zou er allemaal kunnen gebeuren in de wereld en wat betekent dat dan voor onze rol en ons toezicht? Dat is toch wel een thema dat op veel manieren terugkomt in onze manier van werken en dat ik wel heel belangrijk vind.

Joep \& Anna: Dat vooruitkijken is ook een belangrijk onderdeel van jullie visie op toezicht.

Else: Dat klopt. Die visie op toezicht is twee jaar geleden geschreven, net voordat ik binnenkwam. De bedoeling van DNB is, we schrijven ieder jaar als we de financiële begroting vaststellen ook een toezichtvooruitblik. Dan schrijven we op wat we dat jaar aan toezichtdoelstellingen hebben. Wederom was er de behoefte om meer vooruit te kijken. Dat vooruitkijken ook met de sector delen, daar is die visie op toezicht uit ontstaan. Daar zijn drie speerpunten in gekozen, de ene is financieel-economische criminaliteit, dus het integriteitstoezicht. Een andere is wendbaarheid en duurzaamheid. En de derde is technologische ontwikkelingen. We zijn nu bezig om de vooruitblik te actualiseren omdat we vanaf 2021 in een nieuw vierjarig kostenkader komen. Daar zijn we nu mee bezig in onze onderhandelingen met het Ministerie van Financiën. En dan is het wel logisch om daar ook een geactualiseerde vierjarige visie naast te leggen. Maar de drie thema's die ik zojuist noemde, gaan daar zeker weer heel prominent in terugkomen. Daar hebben we al veel aan gedaan in de afgelopen twee jaar, maar we zijn er ook nog lang niet klaar mee.
Joep \& Anna: En morden er nog andere prominente thema's toegevoegd of blijven die drie thema's echt wel de kern?

Else: Die drie thema's blijven wel de kern.

Joep \& Anna: Gezien de tijd, wat er in ieder geval nog moet gebeuren is de estafettevraag. Welke vraag millen jullie aan de Nederlandse Zorgautoriteit meegeven?

Else: Het lijkt mij goed om toch een vraag te stellen die verband houdt met de crisis waar we in zitten. De vorige crisis in 2008, dat was een financiële crisis. Die financiële crisis heeft heel veel impact gehad op DNB. Waar DNB ook veel van geleerd heeft, ook in zijn toezichtaanpak. Daar zijn twee begrippen toen heel prominent in geworden. DNB is een vasthoudende en indringende toezichthouder geworden. Die twee begrippen komen op allerlei manieren in onze huidige manier van werken terug. Maar de crisis waar we nu in zitten, is eigenlijk primair een zorgcrisis. Mijn vraag aan de NZa zou dan zijn: wat heeft dat nou voor impact en gevolgen op de manier waarop de NZa haar toezicht inricht? Welke sterke kanten worden versterkt, en welke kanten vragen om verbetering?

Joep \& Anna: Interessante vraag. We zijn benieumd mat de NZa hiervan zal maken. Voor nu in ieder geval hartelijk bedankt voor je tijd en waardevolle input. 